TITLE:

\title{
Fabrication of SiC lateral super junction diodes with multiple stacking $\mathrm{p}$ - and $\mathrm{n}$-layers
}

\section{$\operatorname{AUTHOR}(S)$ :}

Miura, M; Nakamura, S; Suda, J; Kimoto, T;

Matsunami, $\mathrm{H}$

\section{CITATION:}

Miura, M ...[et al]. Fabrication of SiC lateral super junction diodes with multiple stacking pand n-layers. IEEE ELECTRON DEVICE LETTERS 2003, 24(5): 321-323

\section{ISSUE DATE:}

2003-05

URL:

http://hdl.handle.net/2433/39934

\section{RIGHT:}

(c)2003 IEEE. Personal use of this material is permitted. However, permission to reprint/republish this material for advertising or promotional purposes or for creating new collective works for resale or redistribution to servers or lists, or to reuse any copyrighted component of this work in other works must be obtained from the IEEE. 


\title{
Fabrication of SiC Lateral Super Junction Diodes With Multiple Stacking p- and n-Layers
}

\author{
Mineo Miura, Shun-ichi Nakamura, Jun Suda, Tsunenobu Kimoto, and Hiroyuki Matsunami, Fellow, IEEE
}

\begin{abstract}
Using epitaxial multiple p-n junction structures of 4H-SiC, lateral super junction diodes were fabricated for the first time. The breakdown voltage of the device was $400 \mathrm{~V}$, which is more than $3 \times$ higher than the theoretical value calculated for a device with uniformly-doped drift layer $(130 \mathrm{~V})$, indicating the effective operation of super junction structure.
\end{abstract}

Index Terms-Power device, silicon carbide (SiC), super junction.

\section{INTRODUCTION}

$\mathbf{T}$ HE requirements for power devices are high blocking voltage, low losses and high switching speed. Because of a tradeoff among them, many structures of devices have been developed for various applications. The semiconductor material mainly used for power devices is silicon ( $\mathrm{Si}$ ), but the extensive and intensive progress in $\mathrm{Si}$ processing technologies have brought the device performance close to the theoretical limitation expected from $\mathrm{Si}$ material properties. One way to make a breakthrough beyond the limitation may be the use of another material.

One of the most promising semiconductor materials for power devices is silicon carbide (SiC) [1], owing to its wide bandgap (2.2 to $3.4 \mathrm{eV}$ ), high breakdown field (around $3 \mathrm{MV} / \mathrm{cm})$, and high thermal conductivity $(4.9 \mathrm{~W} / \mathrm{cmK})$. Different from other wide bandgap materials, both $\mathrm{n}$ - and p-type conductivity of SiC can be easily controlled by both epitaxial growth and ion implantation. There have already been reported several SiC Schottky and p-i-n diodes [2] exceeding the limitation of Si.

For further improvement, a super junction (SJ) structure [3] has been proposed, which consists of highly-doped multiple thin p-n junctions. As opposed to ordinary device structures, the voltage is applied along, rather than across, the junctions. Lateral extension (perpendicular to the applied voltage) of the depletion region(s) in the $\mathrm{SJ}$ causes full depletion of the $\mathrm{SJ}$ at a small reverse bias, and further reverse voltages are supported by the fully depleted SJ with almost uniform distribution of electric field, regardless of doping concentration. Therefore, a high doping concentration can be utilized, compared with conventional structures with the same blocking voltage, yielding much

Manuscript received February 4, 2003. This work was supported in part by a Grant-in-Aid (09102009) for Specially Promoted Research, by the Ministry of Education, Culture, Sports, Science and Technology in Japan, and by Feasibility Study of Japan Society for the Promotion of Science. The review of this letter was arranged by Editor J. Sin.

The authors are with the Department of Electronic Science and Engineering, Kyoto University, Kyoto 606-8501 Japan.

Digital Object Identifier 10.1109/LED.2003.812561 lower specific on-state resistance $\left(R_{\mathrm{on}}\right)$. In a simulation for $\mathrm{Si}$ [3], the $R_{\text {on }}$ of SJ structure was predicted to be $100 \times$ lower than that of conventional one.

There have been a few reports on simulation of SiC SJ devices [4], [5], predicting $140 \times$ lower $R_{\text {on }}$ of $4 \mathrm{H}-\mathrm{SiC}$ SJ vertical devices than that of SJ devices made of $\mathrm{Si}$ [4], but no report on fabrication of SiC SJ devices has been presented. A lateral SJ structure is advantageous in device fabrication processes for $\mathrm{SiC}$ : a lateral SJ structure (or multiple thin p-n junctions) can be formed by epitaxial growth [6], [7], because dopant redistribution during epitaxial growth of $\mathrm{SiC}$ is negligible due to small diffusion coefficients in spite of high growth temperatures (normally $1500-1600^{\circ} \mathrm{C}$ ). For lateral SJ devices, the $R_{\text {on }}$ shows a square dependence on the blocking voltage, as opposed to a linear dependence for vertical SJ devices [3]. Therefore, lateral SJ devices will have higher $R_{\text {on }}$ than that of vertical ones. This weak point can, however, be compensated by increasing the number of p-n junction layers in the SJ structure to reduce the $R_{\text {on. }}$. In this letter, simulation and fabrication of SiC lateral SJ diodes are presented.

\section{Numerical Simulation OF SiC SUPER JunCtion}

To simulate SiC SJ device structures, ISE-TCAD was used. As material properties of $4 \mathrm{H}-\mathrm{SiC}$, we assumed a bandgap of $3.26 \mathrm{eV}$, dielectric constant of 9.66 [8], mobilities of electrons and holes in [9], and impact ionization coefficients along the $\langle 0001\rangle$ direction (though we need those in the $\{0001\}$ plane) in [10]. As the breakdown field in $4 \mathrm{H}-\mathrm{SiC}$ shows strong anisotropy [11], the impact ionization coefficients should also have strong anisotropy (not reported yet). The actual breakdown voltage may be estimated by multiplying the ratio of the breakdown fields in the $\{0001\}$ plane and along the $\langle 0001\rangle$ direction (approximately $0.75[11])$.

Different from conventional device structures, the blocking voltage of SJ devices does not depend on the doping concentration, but solely on the length of the SJ structure along which the voltage is applied. From the limitation of our lithography system, we selected the length of SJ to be $10 \mu \mathrm{m}$. The corresponding blocking voltage was calculated to be $1.3 \mathrm{kV}$, with the anisotropy of breakdown field taken into account. The $R_{\text {on }}$ decreases with increasing doping concentration in the SJ, but an imbalance of doping concentration in the SJ significantly reduces the blocking voltage [3], [4]. From the uniformity and controllability of doping during our epitaxial growth, we selected the doping concentration of $4 \times 10^{17} \mathrm{~cm}^{-3}$. The corresponding optimal thickness of the SJ layers was calculated to be $0.4 \mu \mathrm{m}$. An important simulation result is that the thickness 


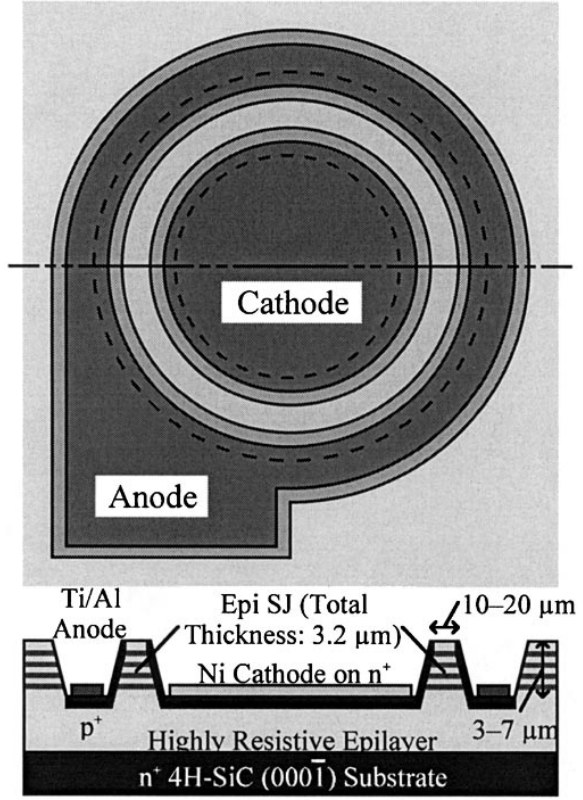

Fig. 1. Schematic structure of fabricated devices. The device active area is indicated by dashed circles.

of the outermost layers in a finite SJ should be halved; otherwise incomplete depletion in the outermost layers distorts the electric field distribution and reduces the breakdown voltage less than half for the ideal case. With a total thickness of $3.2 \mu \mathrm{m}$, the $R_{\text {on }}$ was calculated to be $0.3 \mathrm{~m} \Omega \mathrm{cm}^{2}$. Details of the device simulation will appear elsewhere.

\section{DEVICE FABRICATION}

Fig. 1 shows the schematic cross section of the fabricated device. On $(000 \overline{1}) \mathrm{C} 4 \mathrm{H}-\mathrm{SiC} \mathrm{n}^{+}$substrates with $8^{\circ}$ of inclination toward $\langle 11 \overline{2} 0\rangle$, a highly-resistive (HR) layer and the SJ structure with four n-layers and five p-layers were successively grown by chemical vapor deposition in a horizontal cold-wall reactor [12]. The HR layer was designed to isolate the devices from the conducting substrates. The source gases were $\mathrm{SiH}_{4}$ $(0.50 \mathrm{sccm})$ and $\mathrm{C}_{3} \mathrm{H}_{8}(0.33 \mathrm{sccm})$, and the carrier gas was $\mathrm{H}_{2}$ (3 slm). The growth temperature was $1500^{\circ} \mathrm{C}$. Under these conditions, the growth rate was about $3.0 \mu \mathrm{m} / \mathrm{h}$. The thickness of the HR layer was about $9 \mu \mathrm{m}$. The thickness of each layer in the SJ structure was $0.4 \mu \mathrm{m}$, except for the outermost p-layers for which the thickness was halved to ensure full depletion. The doping concentrations of n-layers in the $\mathrm{SJ}$ were designed to be $4 \times 10^{17} \mathrm{~cm}^{-3}$ with $\mathrm{N}_{2}$, and those of p-layers were varied in the range of $2.5-6.5 \times 10^{17} \mathrm{~cm}^{-3}$ with $\mathrm{B}_{2} \mathrm{H}_{6}$.

A ring-like mesa structure made of SJ, with the cathode on the interior and the anode on the exterior, was employed, as shown in Fig. 1. The inner and outer diameters of the SJ ring were $165-170 \mu \mathrm{m}$ and $180-185 \mu \mathrm{m}$, respectively, at the top of mesa. The SJ length was $10-20 \mu \mathrm{m}$. Because of a limited vertical depth (about $3 \mu \mathrm{m}$ ) of ion implantation into the contact regions, sloped sidewalls for the anode and cathode regions were formed on both of the inner and outer sides. To form the slope, molten $\mathrm{KOH}$ etching at $460-480{ }^{\circ} \mathrm{C}$ using an $\mathrm{Al}$ mask [13] was

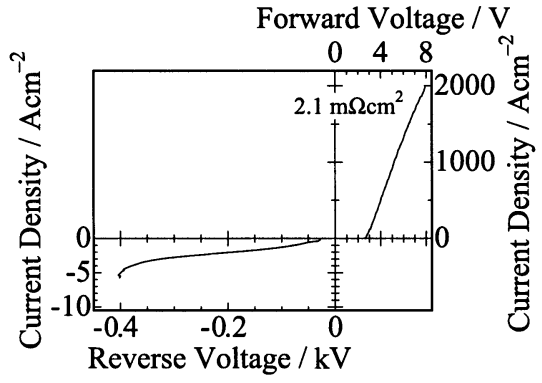

Fig. 2. Typical $I-V$ characteristics of fabricated diodes.

employed to form the mesa with 3-4 $\mu \mathrm{m}$ of height. The anode and cathode regions were formed by $\mathrm{Al}$ (average concentration: $1 \times 10^{20} \mathrm{~cm}^{-3}$ ) and $\mathrm{P}$ (average concentration: $2 \times 10^{20} \mathrm{~cm}^{-3}$ ) ion implantation, respectively, at $300{ }^{\circ} \mathrm{C}$. After activation annealing at $1750{ }^{\circ} \mathrm{C}$ for $30 \mathrm{~min}$ in an $\mathrm{Ar}$ ambience, the samples were passivated with a thermal oxide grown at $1100^{\circ} \mathrm{C}$ for 15 min in a dry ambience. As contact metals for the anode and cathode, $\mathrm{Al} / \mathrm{Ti}$ and $\mathrm{Ni}$, respectively, were thermally evaporated, and they were simultaneously sintered at $800{ }^{\circ} \mathrm{C}$ for $10 \mathrm{~min}$ in an Ar ambience.

\section{EleCtrical Properties of Diodes}

Fig. 2 shows typical current-voltage $(I-V)$ characteristics of the fabricated $\mathrm{p}^{+} / \mathrm{SJ} / \mathrm{n}^{+}$diodes. For forward bias conditions, very high on-state current densities of $100 \mathrm{~A} / \mathrm{cm}^{2}$ at $3.0 \mathrm{~V}$, $500 \mathrm{~A} / \mathrm{cm}^{2}$ at $3.9 \mathrm{~V}$ and $1000 \mathrm{~A} / \mathrm{cm}^{2}$ at $5.0 \mathrm{~V}$ were obtained. The $R_{\text {on }}$ was $2.1 \mathrm{~m} \Omega \mathrm{cm}^{2}$, where the device active area was defined based on the foot of SJ mesa ring, as schematically indicated by dashed circles in Fig. 1. The obtained $R_{\text {on }}$ is about $10 \times$ larger than the value (about $0.3 \mathrm{~m} \Omega \mathrm{cm}^{2}$ ) predicted by our numerical simulation. The discrepancy between the measured and predicted $R_{\mathrm{on}}$ s may be attributed to the high sheet and/or contact resistances in the contact regions, which were not taken into account in the simulation. It should also be noted that our definition overestimates the device active area by $2-3$ times, because we included 5-10 $\mu \mathrm{m}$ for each contact region. With microfabrication technologies, the $R_{\text {on }}$ should be much reduced.

For reverse bias conditions, the maximum breakdown voltage of $400 \mathrm{~V}$ was obtained. This breakdown voltage is more than three times higher than that of conventional (uniformly-doped) p-n diodes with such high doping concentrations $\left(4 \times 10^{17} \mathrm{~cm}^{-3}\right)$, which should be at most $130 \mathrm{~V}[11]$, indicating that the SJ structure operates effectively.

As mentioned before, the breakdown voltage may be reduced by charge imbalance. However, we did not see a systematic change of breakdown voltage when the doping in the p-layers was varied. Therefore, the breakdown voltage was probably reduced by an insufficient device fabrication process: Because of the poor controllability of $\mathrm{KOH}$ etching process, the mesas for most of the fabricated diodes were too high and eventually the HR layers were too thin (mostly less than $5 \mu \mathrm{m}$ ), causing premature breakdown (at less than $650 \mathrm{~V}$ even without electric field crowding) in the HR layer. The next step is to develop a reliable and controllable device fabrication process. 


\section{CONCLUSION}

Using epitaxial multiple p-n junction structures of $4 \mathrm{H}-\mathrm{SiC}$, lateral SJ diodes were designed, and fabricated for the first time. Owing to relatively high doping concentrations in the SJ region $\left(4 \times 10^{17} \mathrm{~cm}^{-3}\right)$, very high on-state current densities of $500 \mathrm{~A} / \mathrm{cm}^{2}$ at $3.9 \mathrm{~V}$ and $1000 \mathrm{~A} / \mathrm{cm}^{2}$ at $5.0 \mathrm{~V}$ were obtained. The breakdown voltage of the device was $400 \mathrm{~V}$, which is more than $3 \times$ higher than that of conventional (uniformly-doped) devices $(130 \mathrm{~V})$ with such high doping concentrations, indicating the effective operation of SJ structure. These results indicate the prospect of SiC lateral SJ structures, after the device fabrication processes are well established.

\section{REFERENCES}

[1] M. Bhatnagar and B. J. Baliga, "Comparison of 6H-SiC, 3C-SiC, and $\mathrm{Si}$ for power devices," IEEE Trans. Electron Devices, vol. 40, pp. 645-655, 1993.

[2] R. Singh, J. A. Cooper, Jr., M. R. Melloch, T. P. Chow, and J. W. Palmour, "SiC power Schottky and PiN diodes," IEEE Trans. Electron Devices, vol. 49, pp. 665-672, Apr. 2002.

[3] T. Fujihira, "Theory of semiconductor superjunction devices," Jpn. $J$. Appl. Phys., vol. 36, pp. 6254-6262, 1997.
[4] K. Adachi, C. M. Johnson, H. Ohashi, T. Shinohe, K. Kinoshita, and $\mathrm{K}$. Arai, "Comparison of super-junction structures in $4 \mathrm{H}-\mathrm{SiC}$ and $\mathrm{Si}$ for high voltage applications," Mat. Sci. Forum, vol. 353-356, pp. 719-722, 2001.

[5] — " "Super-junction device forward characteristics and switched power limitations," Mat. Sci. Forum, vol. 389-393, pp. 1251-1254, 2002.

[6] J. Suda, S. Nakamura, M. Miura, T. Kimoto, and H. Matsunami, "Scanning capacitance microscopy of $\mathrm{SiC}$ multiple pn junction structure grown by cold-wall chemical vapor deposition," Mat. Sci. Forum, vol. 389-393, pp. 659-662, 2002.

[7] — "Scanning capacitance and spreading resistance microscopy of SiC multiple-pn-junction structure," Jpn. J. Appl. Phys., vol. 41, pp. L40-L42, 2002.

[8] L. Patrick and W. J. Choyke, "Static dielectric constant of SiC," Phys. Rev. B, vol. 2, pp. 2255-2256, 1970 .

[9] W. J. Schaffer, G. H. Negley, K. G. Irvine, and J. W. Palmour, "Conductivity anisotropy in epitaxial $6 \mathrm{H}$ and $4 \mathrm{H} \mathrm{SiC,"} \mathrm{Mat.} \mathrm{Res.} \mathrm{Soc.} \mathrm{Symp.}$ Proc., vol. 339, pp. 595-600, 1994.

[10] A. O. Konstantinov, Q. Wahab, N. Nordell, and U. Lindefelt, "Ionization rates and critical fields in $4 \mathrm{H}$ silicon carbide," Appl. Phys. Lett., vol. 71, pp. 90-92, 1997.

[11] S. Nakamura, H. Kumagai, T. Kimoto, and H. Matsunami, "Anisotropy in breakdown field of 4H-SiC," Appl. Phys. Lett., vol. 80, pp. $3355-3357,2002$

[12] H. Matsunami and T. Kimoto, "Step-controlled epitaxial growth of SiC: High quality homoepitaxy," Mat. Sci. Eng., vol. R20, pp. 125-166, 1997.

[13] Q. Wahab, H. Kosugi, H. Yano, T. Kimoto, and H. Matsunami, " $4 \mathrm{H}-$ and $6 \mathrm{H}-\mathrm{SiC}$ MOSFETs fabricated on sloped sidewalls formed by molten KOH etching," Mat. Sci. Forum, vol. 389-393, pp. 1215-1218, 2002. 